\title{
Figuras de la distancia en la escritura crítica. Mínima genealogía en tres escansiones
}

\author{
RODRIGO MONTENEGRO Universidad Nacional de Mar del Plata - CONICET, Argentina \\ ORCID 0000-0002-3727-6401 \\ rdmontenegro@gmail.com
}

\section{Resumen}

Propongo un itinerario genealógico a través de textos centrales para los estudios literarios a fin de focalizar el problema de la distancia crítica como ideologema paradójico y constitutivo. Para ello planteo tres escansiones: primero, una revisión de los textos fundacionales del formalismo ruso junto a las intervenciones benjaminianas en las primeras décadas del siglo XX; luego, una aproximación a las renovaciones del lenguaje crítico en torno al espacio de la revista Tel Quel y el inicio de la propuesta agambeniana; finalmente, una revisión de la actualidad del ensayo crítico y la negatividad en Damián Tabarovksy y Alberto Giordano, escritores argentinos contemporáneos. El recorrido focaliza diversas escenas y momentos culturales a fin de corroborar la persistencia del problema de la distancia y la negatividad, nociones que ofrecieron un marco epistemológico para el experimentalismo y las modulaciones de la escritura crítica. Al observar estas intervenciones es posible advertir una zona de indistinciones entre prácticas de pensamiento y literarias, en la cual la crítica desarrolla una política inmanente.

Palabras clave: distancia / crítica / negatividad/ genealogía/ Argentina

\section{Figures of distance in critical writing. Minimum genealogy in three scansions Abstract}

I propose a genealogical itinerary through central texts for literary studies in order to focus on the problem of critical distance as a paradoxical and constitutive ideologeme. For this I propose three scansions; first, a review of the founding texts of Russian formalism together with Benjaminian interventions in the first decades of the 2oth century; then an approach to the renewals of critical language around the space of the magazine Tel Quel and the beginning of the Agambenian proposal; finally, a review of the topicality of the critical essay and negativity in Damián Tabarovksy y Alberto Giordano, contemporary Argentine writers. The tour focuses on various cultural scenes and moments in order to corroborate the persistence of the problem of distance and negativity, notions that offered an epistemological framework for experimentalism and the modulations of critical writing. When observing these interventions it is possible to notice a zone of indistinctions between thought and literary practices, in which criticism develops an immanent politics.

Key words: distance / criticism / negativity / genealogy / Argentina

Recibido: 28/7/2021. Aceptado: 12/8/2021

Para citar este artículo: Montenegro, R. (2021). Figuras de la distancia en la escritura crítica. Mínima genealogía en tres escansiones. El taco en la brea, (14) (junio-noviembre). Santa Fe, Argentina: UNL. eoo53

DOI: 10.14409/tb.2021.14.e0053 


\section{Apertura}

El punto de partida para considerar la vigencia u obsolescencia de una escritura crítica y experimental en el presente quizás deba explorar las modulaciones que dieron forma a la modernización de los estudios literarios durante el siglo XX. A partir de este inicio, y de los avatares de su desplazamiento, propongo una mirada que intenta observar marcas en un mapa en absoluto riguroso, compuesto por escansiones arbitrarias y asincronías significativas. Por un lado, entonces, se trata de contrastar ensayos centrales para la teoría literaria que permiten tener en cuenta los pulsos e hibridaciones de la crítica, su problemática historicidad y la dificultad para definir, tachar o reformular el ideologema de la distancia como requerimiento de su práctica. A partir de este recorrido es factible considerar cómo, aun en el contexto argentino, la noción de negatividad junto a ciertas formas de escritura resistentes y experimentales resuenan en la práctica de autores contemporáneos; incluso para advertir en su insistencia la reformulación de esos conceptos en la actualidad de una sociedad controlada y definitivamente atravesada por la homogeneización técnica de la vida.

En este contexto, el ensayo crítico y la ficción experimental bien pueden considerarse al interior de una genealógica específica, la cual ha elaborado una productiva zona de indistinciones. De modo que, al trazar algunos detenimientos en este itinerario quizás sea posible enfocar una memoria crítica actualizada entre ciertas escrituras y actos de pensamiento para advertir el signo de su transformación y la persistencia de sus políticas.

\section{Correlaciones: del extrañamiento al distanciamiento}

Aun a riesgo de caer en una aparente contradicción epistemológica o sucumbir al vértigo del azar, quizás la proximidad conceptual que parece unir a los primeros ensayos del formalismo ruso y las relecturas de Roman Jakobson, junto a las indagaciones que Walter Benjamin realizara sobre el teatro épico de Bertolt Brecht permita esclarecer uno de los cruces fundamentales entre el pensamiento y su cercanía con las artes. En este intersticio sin dudas problemático se encuentra la zona de indeterminaciones en la que se emplaza la crítica, ya sea en diálogo con las herramientas provistas por una lingüística modernizada o las irradiaciones del materialismo dialéctico.

No es casual, entonces, que estos episodios emblemáticos y fundacionales para la teoría literaria hayan tomado como foco de interés la funcionalidad de la distancia y el extrañamiento en tanto nociones a especificar, a fin de explorar sus potencialidades en la descripción de las artes verbales. Tampoco es casual que el interlocutor de cada momento teórico, ya sea en el ámbito alemán o eslavo, haya sido el arte de vanguardia, cuya condición crítica sobre la historicidad de la institución del arte ha sido cristalizada en el célebre ensayo de Peter Bürger (2010) y retomada por Hal Foster (2001). De modo que el experimentalismo vanguardista y el ensayo teórico habrían formado parte de una misma escena en la cual se consolida la emergencia de la crítica.

No es azaroso, por lo tanto, encontrar en la entrada referida a «extrañamiento» elaborada por Christopher Norris para el voluminoso y pormenorizado Diccionario de teoría crítica y estudios culturales (2002) compilado por Michael Payne, la indicación de este "paralelismo» (281). Esta correlación también ha sido advertida por Lucía Hellín Nistal (2016) quien sostiene que junto a las correspondencias teóricas debe advertirse una adecuación estrictamente sociopolítica, que se explica como parte de las discusiones entre «el formalismo y el realismo socialista en el seno de dos regímenes comunistas, la Unión de Repúblicas Socialistas Soviéticas (URSS) y la República 
Democrática Alemana (RDA), con apenas dos décadas de diferencia» (2016:463-464). Si existe una zona común entre los conceptos de ostranenie y verfremdungseffekt, entonces la posibilidad de advertir instancias de sentido crítico en las obras de arte configura una obstinación no solo del arte de vanguardia, sino también de sus lectores privilegiados y contemporáneos.

Este panorama de indistinciones se exaspera al considerar la reversibilidad de las posiciones entre escritores y teóricos en ámbitos de reflexión compartida, condición señalada por uno de los protagonistas de esta irrupción. «No por azar el Círculo lingüístico de Moscú contó entre sus miembros a poetas» (1978:9), escribió Roman Jakobson en su mirada retrospectiva de 1965 al referir la composición de la OPOIAZ, grupo que asedió el problema de la creación verbal en el ámbito eslavo. Resulta evidente que, tal como ha señalado José Amícola, existió una «completa afinidad entre el formalismo ruso y el futurismo» (1997:50). Ahora bien, en un contexto completamente diverso, pero en un sentido análogo, Benjamin reconocía en el teatro de Brecht el lugar del actor «del lado del filósofo» (1998:28), dando forma a una comunidad de creación y pensamiento que también puede rastrearse en sus afinidades con poetas surrealistas claramente visibles en «El autor como productor» (1998).

Por ello, estas inflexiones en torno a una formulación metodológica que de modo transversal se repite en las primeras consideraciones sobre una mirada distanciada o extrañada, según el caso, corrobora el fundamento de una imaginación crítica que trasciende el juicio valorativo y esencialista sobre las bellas letras, para construir en su lugar una escritura y un saber inmanentes, en absoluto clausurados en un cientificismo opaco sino abiertos al intercambio de posiciones de enunciación. De ahí que el problema de la distancia y la percepción extrañada haga visibles formas específicas de creación conceptual al interior de la escritura crítica, ya sea que enfoque la distinción entre el lenguaje automatizado y la lengua poética estudiada por el formalismo ruso, o las formas pasivas de la representación burguesa y el descubrimiento de situaciones alejadas del espectador en el caso benjaminiano. A uno y otro lado de las retóricas críticas (y sus fundamentos teóricos), estas operaciones insisten en identificar modulaciones distantes de lectura, de expectación y creación que sin dudas forman parte de una potencia inscripta en las artes y reverbera en la reflexión que las desea como objeto.

La elaboración conceptual de esta distancia, a todas luces polisémica, señala el gesto crítico de las vanguardias históricas frente a modos canónicos de representación. Así, en los ensayos de Benjamin sobre Brecht el interés en torno a las formas disensuales de creación actuaba como contracara de las ilusiones imitativas, «naturalistas» (Benjamin 1998:36), que bloquean el principio crítico de la conciencia. «El teatro épico», sostenía Benjamin, «se mantiene ininterrumpidamente consciente, de manera viva y productiva (...) Y por eso resulta capaz de tratar los elementos de lo real en el sentido de una tentativa experimental» (20). Existiría, entonces, una correlación fundamental en la cual el experimentalismo vanguardista proporciona el sedimento para la construcción de un arte consciente y, por lo tanto, conectado a expresiones vivas de la realidad. Este encuentro entre prácticas experimentales ubicadas «en la cumbre de la técnica» (21) y el ensayo benjaminiano construyen una forma específica de productividad crítica, ya no emplazada en el ilusionismo mimético o la verificación filológica, sino en el descubrimiento de situaciones a partir «de la interrupción del proceso de la acción» (20). Esta suspensión, este corte, constituye el centro del problema. Al efectuar una creación de la distancia Benjamin procuraba leer el gesto experimental en su «significación social», en tanto que el acto artístico da cuenta 
de «la aplicabilidad de la dialéctica» (28). A través de estos desplazamientos se expanden las correlaciones entre el gesto crítico del arte experimental, los usos de la teoría y sus eventuales consecuencias en el campo social. Al indagar el procedimiento brechtiano Benjamin encontraba una potencia fundamentalmente crítica que, asimismo, se irradiaba hacia su escritura y trazaba su horizonte metodológico: «Un comportamiento dialéctico inmanente es lo que a modo de relámpago se pone en claro en una situación (...) La situación que el teatro épico descubre es la dialéctica en estado de detención» (28-29). El ensayo benjaminiano señalaba en esta suspensión un acontecimiento en sí mismo literario (poiético) y filosófico, y por lo tanto conceptualizado en su condición inmanente. La situación brechtiana y la iluminación crítica sugerida por Benjamin se elaboran en una correspondencia que toma cuerpo en la escena teatral (y en la escena teórica) para componer «Otro modo de representar, más distanciado» (40), valorado tanto por su innovación como en su capacidad en la reactivación de la conciencia. Tal como refería Benjamin «Se trata sobre todo de descubrir primero las situaciones. (Podría igualmente decirse: se trata de extrañarlas). Ese descubrimiento (extrañamiento) de situaciones se realiza por medio de la interrupción del proceso de la acción» (36). Con estos argumentos el ensayo deshace los modos miméticos y progresivos para instalar en su lugar un uso de la distancia eminentemente crítico.

En una modulación significativamente correspondiente, aunque en otra escena cultural, Víctor Shklovski afirmaba en 1917 que «la finalidad del arte es dar sensación del objeto como visión y no como reconocimiento» (1978:60); de ahí que los procedimientos constituyeran para el formalista el centro del extrañamiento y el fundamento de su distancia contra la automatización de la vida. En rigor, la ostranenie proponía una intervención teórica que interpretaba los lenguajes literarios a través de «la dificultad y la duración de la percepción» (60), considerada propósito de la experiencia artística lanzada contra la celeridad y la abstracción de la economía comunicativa. Puede advertirse entonces que, más allá de la vocación modernizadora del análisis formalista, cuya preocupación capital se encontraba en recuperar «para sí el derecho a la inmanencia» (Amícola, 1997:58), el alcance del método se expande hacia la construcción de un régimen de visibilidad, historicidad y transformación de las obras literarias y de sus potencialidades para crear imágenes resistentes a los usos triviales, e incluso observar su intersección crítica en la vida social. Por esto, considerar el «método formal» (Eichenbaum, 1978:21), tal como lo nombró Boris Eichenbaum en 1925, solo desde su componente lingüístico resultó siempre reductivo, y de hecho el reclamo de autonomía para la teoría nunca dejó de lado su carácter inacabado o, más precisamente, proyectivo, tal como observara Eichenbaum «La ciencia evoluciona, y nosotros con ella» (1978:53). Ya en su texto fundacional, Shklovski consideró el carácter inmanente del arte literario implicado en un objetivo que trasvasaba los alcances de un mero estudio retórico: «Para dar sensación de vida, para sentir los objetos, para percibir que la piedra es piedra, existe eso que se llama arte» (1978:60). Esta amplificación conceptual del extrañamiento, de la evidente distancia obrada entre el lenguaje algebraico y la densidad de la palabra literaria, enlaza los artificios técnicos de evidente naturaleza lingüística con sus capacidades para crear afectos singulares sobre la vida, en un sentido amplio, y sobre la percepción, en un sentido restringido. De esto se desprende la advertencia de Christopher Norris, quien sostiene que el extrañamiento concebido por el formalismo se implica necesariamente con una expansión del campo inmanente, dado que «Para Shklovski, esta idea tenía consecuencias éticas, además de estéticas y literarias» (2002:281). 
Esta zona de interferencias y solapamientos tramada en torno a las nociones de «extrañamiento» $\mathrm{y}$ «distanciamiento» es elaborada tanto en el Diccionario... de Michael Payne como en el estudio de José Amícola; y si bien en el volumen compilado por el norteamericano las similitudes se sostienen, en su capítulo dedicado a «El arte como artificio» reunido en De la forma a la información, Amícola señala una crucial distinción, al considerar que el verfremdungseffekt no se encontraría "primariamente basado en una percepción estética» (1997:58), sino sería el resultado de una intervención sobre la conciencia del espectador. Por su parte, el contrapunto entre las nociones es interpretado por Hellín Nistal en los términos de un debate sobre las transformaciones literarias; de modo que para el formalismo «la historia de la literatura avanza por la necesidad de innovaciones una vez que los procedimientos literarios caen en el automatismo» (2016:489), por su parte, para el teatro de Brecht «la evolución literaria viene dada por los acontecimientos históricos y la propia evolución de las estructuras» (489). No obstante, ya sea en la acepción brechtiana reelaborada por Benjamin, o la especificidad técnica del uso formalista, es posible corroborar hasta qué punto estos mestizajes conceptuales tomaron relevancia durante las primeras décadas del siglo pasado, en especial al postularse contra modos automatizados del lenguaje y las retóricas burocráticas del realismo naturalista, así como a las condiciones preteóricas de la crítica. Con todo, el paralelismo conceptual aludido por Norris, recogido y matizado por Amícola y Hellín Nistal, permite señalar una zona común en los estudios literarios durante el inicio del siglo XX, una escena que contenía y mestizaba formas de la escritura crítica con el arte de vanguardia.

Estas intervenciones fundacionales permitieron la creación de un campo cuyo fundamento teórico (lingüístico o dialéctico), posibilitó una figuración de la distancia sin dudas compartida por el experimentalismo vanguardista y el ensayo crítico. Al insistir en estas figuras y advertir sus correlaciones es posible encontrar el primer detenimiento de una política de la crítica y la experimentación, cuyos procedimientos consistieron en extrañar los modos de la percepción y, en última instancia, de la conciencia. Estas escenas permiten proyectar otro momento singular de la discusión, cuando este antiguo problema regresaba a la teoría literaria, para expandir y confundir objetos de reflexión y escritura.

\section{Campo de indistinciones: escritura, crítica, negatividad}

En un sentido general, las derivas del elusivo discurso sobre el objeto literario en sus diversos avatares a lo largo del siglo XX han corroído las pretensiones de cientificidad para encontrar, en su lugar, una indagación en torno a la función de la crítica y su proximidad con las prácticas de escritura.

Uno de los textos emblemáticos en ese itinerario, en tanto cataliza una serie de controversias en el campo cultural francés de la década de 1960 fue, sin dudas, Crítica y verdad de Roland Barthes. Allí, las posiciones desplegadas contra la tradición académica y filológica de su adversario Raymond Picard constituyeron el plafón para observar hasta qué punto la acción conjugada del estructuralismo y el psicoanálisis dio forma a una teoría de la crítica, o de lo que barthesianamente podría denominarse semiología literaria, en la cual se inscribía un componente creativo. A través de la conceptualización del lenguaje como espacio estructuralmente abierto y sin centro Barthes podía reclamar la doble funcionalidad «poética y crítica de la escritura» (2000:47); de ahí que, más allá de la polémica coyuntural, el ensayo efectuara un pensamiento (y una textualidad) 
que insistía en pregonar la indistinción fundamental entre literatura y teoría, prácticas que, tal como advierte Sonia Bertón se consideraban «no sólo inseparables sino, en algún punto, indiscernibles» (2013:3). Crítica y verdad permite observar la modulación polémica de estas consideraciones en las que resuenan posiciones compartidas con los integrantes de la revista Tel Quel. En este sentido, tal como indica Bertón, las nociones de «sujeto y lenguaje, teoría y literatura, política y escritura son, para los telquelistas, configuraciones que se sustentan en la indefinición de sus límites» (3). En ese aparente desborde terminológico irrumpe la «nueva crítica» (Barthes, 2000:9) en tanto potencia contestataria al «Estado literario» (13), a su disciplinamiento de los lenguajes; contrariamente la crítica sería, ante todo, práctica de escritura, cuyo horizonte utópico es la creación de un campo transdisciplinar, resultado de la alteración de las taxonomías que rigen sobre el orden discursivo. El ensayo de Barthes era explícito al respecto: «Nada es más esencial para una sociedad que la clasificación de sus lenguajes. Cambiar esa clasificación, desplazar la palabra, es hacer una revolución» (47). Su dictamen inscribía el gesto político de una renovación en el campo de la teoría literaria, aunque lejos de vindicar una creación ex nihilo dejaba el rastro de su propia genealogía: «Durante dos siglos, el clasicismo francés se ha definido por la separación, la jerarquía y la estabilidad de sus escrituras, y la revolución romántica se ha considerado a sí misma como un desorden de clasificación» (47). Esta remisión a la fractura ocurrida en el final del siglo XVIII en torno al ideal clásico de las bellas letras no constituye, sin dudas, un patrimonio de la cultura francesa y, de hecho, será el punto de partida para Giorgio Agamben en un ensayo que apenas algunos años más tarde se inscribiría en la misma genealogía.

La reflexión en torno a la escritura en el sentido otorgado por Barthes abandona cierta idea de subjetividad que se encuentra en la infraestructura conceptual de los vínculos entre sujeto y lenguaje, y posee consecuencias concretas en sus capacidades para describir y explicar el mundo. Así, el «alejamiento del Autor» (1994:68) planteaba un escenario en el cual a la incidencia del psicoanálisis se unían las resonancias brechtianas; «se podría hablar, siguiendo a Brecht, de un auténtico distanciamiento» (68), escribía Barthes para corroborar la inestabilidad de la noción de sujeto, cristalizada en la célebre «muerte del Autor» (81). La inexistencia de una instancia de sentido pleno en las prácticas de lectura conduce a la crítica hacia un ejercicio perifrástico «dígase lo que se diga de la obra, queda siempre, como en su primer momento, lenguaje, sujeto, ausencia» (Barthes, 2000:75). En ese decir de la palabra crítica, en su rodeo digresivo, se hace tangible la dimensión de una escritura expansiva que, sin embargo, nunca llega a capturar su objeto. Esta condición asintótica crea una escritura que no renuncia a la metáfora (la crítica sería anamorfosis, palabra desdoblada, etc.), reconfigurando el tópico de la distancia para, en última instancia, reducirla infinitamente.

Este enlace nunca completamente realizado entre la productividad crítica y la literaria conforma la indagación más enigmática del ensayo, exacerbada en el apartado que Barthes dedica a la especulación entorno a una «ciencia de la literatura» (2000:58). Tal como advierte Evelin Arro (2008), el carácter incierto que rodea a la propuesta no puede soslayarse, en tanto despierta reparos al momento de conjeturar un saber positivo, objeto de una especial denostación por parte del propio Barthes. La detención que el ensayo consagra a una ciencia por venir, ocupada en «las variaciones de sentidos engendradas y, si puede decirse, engendrables por las obras» (Barthes, 2000:59) encuentra el punto estrictamente hipotético y paradójico de un saber imaginado como posibilidad, imitando y reescribiendo el gesto saussureano, el cual conjeturó «concebir una 
ciencia que estudie la vida de los signos en el seno de la vida social» (Saussure, 1945:43). La ciencia literaria aludida por Barthes adopta, entonces, la fisonomía de un saber por construir, a cuya base lingüística debe superponerse la incidencia lacaniana diseminada en Crítica yverdad. Esta doble valencia resquebraja toda positividad cientificista para desplegar en su lugar una teoría de la crítica que ofrece una imagen incómoda y problemática del lenguaje (y del sujeto). Atravesado por esta epistemología, el gesto de Barthes da forma a una crítica que derrumba la posibilidad de una restauración filológica para encontrar en la escritura el espacio nodal de una indeterminación. Tal como sostiene Arro, «la escritura de Barthes cede sin estridencias al poder creador de la palabra simbólica» (2008:47), por esto, y más allá del ímpetu científico barthesiano (¿o sería, quizás, un desliz?), resulta evidente, que, en su ejercicio de la crítica como en la teoría que sostiene su práctica, toma cuerpo una palabra en la que «prevalece la fuerza de la incertidumbre (17).

Esta vindicación de la crítica como escritura establece un espacio simbólico y creativo cuya potencia excede la conceptualización realizada por Barthes. Dos años más tarde a la aparición de Crítica y verdad se publica en 1968 Teoría de conjunto, compilación de ensayos que plasma el alcance, al menos pretendido, de la producción teórica de los integrantes de la revista Tel Quel, y permite advertir, tal como sostiene Asensi Pérez, la voluntad de ceración de un «espacio». «División del conjunto», texto-manifiesto que iniciaba el libro colectivo, sirve como contundente testimonio de una constelación de nombres que, enfocando diversos saberes, se reunían en la indistinción productiva del concepto de escritura, tal como fue asediado por los telquelistas. Foucault, Derrida y Barthes oficiaron como signos para inscribir las primeras tres consignas del manifiesto: «La escritura en su funcionamiento productor no es ninguna representación», «La escritura escande la historia», «La escritura ya no es un signo de la verdad» (Redacción de Tel Quel, 1971:9-10). La insistencia en el concepto demuestra la potencia de su significación, y su carácter transversal en cada una de las indagaciones teóricas. Esta dimensión omnipresente de la escritura como condición imprescindible en una teoría de la crítica se sostiene incluso en el contexto inmediato a la revuelta de 1968, con consecuencias directas para la institución universitaria, hecho que evidencia hasta qué punto la imagen de la revolución adoptaba para los telquelistas una doble valencia teórica y política.

Con relativa independencia de los objetos o disciplinas sometidas a examen (filosofía, historia, marxismo, literatura...), los ensayos reunidos en Théorie d'ensemble desplegaban un pensamiento que, ante todo, examinaba sus propias condiciones de emergencia, sus limitaciones e historicidad, para poner en jaque la tajante división entre teoría y práctica. De hecho, tal como advierte Asensi Pérez, la homogeneidad de los ensayos se encuentra en el constante asedio a la «escritura textual» (2006:123), considerada en su perfil disruptivo: «Todo el volumen está atravesado por un imperativo teórico (...) establecer una autoreflexividad textual como condición insoslayable de la revolución» (124). Sin embargo, en lugar de presentarse como novedad radical, «División del conjunto» proponía la recuperación de momentos que antecedían a la irrupción de su práctica; por un lado, las renovaciones epistemológicas del siglo XIX, por otro, la experiencia del arte vanguardista, los epígrafes de Marx y Mallarmé actúan como signos explícitos de esta operación. La «Teoría de la literatura» (Redacción de Tel Quel, 1971:7) diagramada en 1968 plegaba temporalidades con el objetivo de alinear su propia creación de «conceptos decisivos» (7); el primero de ellos, «escritura» (7), oficiaba como apertura hacia un campo heterogéneo sobre cuyas divisiones se establecían redes y trazos de contacto. 
En este contexto la pregunta por la distancia, tal como fue formulada durante las primeras décadas del siglo XX, se desplazaba para ser enmarcada en una teoría de la textualidad. Su pervivencia encontraba una modulación singular en el ensayo de Michel Foucault, «Distancia, aspecto, origen», fechado en 1963 e incluido en Teoría de conjunto, el cual tomaba como punto de partida la ponderación crítica sobre la narrativa Alain Robbe-Grillet para contraponer sus diferencias con los telquelistas. Interesa en este punto la modalidad autorreflexiva desplegada por Foucault al interior de un ensayo crítico, en especial su focalización en el concepto de ficción, palabra «tantas veces usada y luego abandonada, y no sin temor» (1971:21). Foucault intentaba desmarcarse de las triviales imantaciones que vinculan la ficción con el psicologismo de la «imaginación», el «sueño», la «invención» (21), así como la tajante oposición entre «dos dinastías: la de lo Real y la de lo Irreal» (21). Contra esa visión el ensayo proponía una potencia específica de lo ficticio, aquello «que nombra las cosas, las hace hablar y da, en el lenguaje, su ser partido por el soberano poder de las palabras» (22). Al establecer una genealogía que conducía hasta el surrealismo de André Breton, Foucault describía la ficción en los términos de una experiencia, una creación de lo real en el lenguaje, lejos de cualquier burda taxonomía opositiva; esta conceptualización "proporciona una distancia que no pertenece ni al mundo, ni a la mirada, ni a la interioridad» (21). De ahí que la fractura del ordenamiento disciplinar diera lugar a una confusión sostenida como paradoja irresoluble: «Si me preguntaran la definición de lo ficticio, respondería sin titubear: la nervadura verbal de lo que no existe tal cual es» (23). El valor oximorónico de la definición desestima, por supuesto, toda pretensión de clausura, y en su lugar propone «dialectizar (...) la ficción» (23), es decir, abrir un campo en el cual las consideraciones sobre la subjetividad y lo imaginario se involucren en una nueva inflexión:

Tendríamos que substituir todo este léxico de mescolanza por el vocabulario de la distancia y, luego, hacer ver que lo ficticio es un alejamiento propio del lenguaje: un alejamiento que tiene su propio lugar dentro de él, pero que además lo muestra, lo dispersa, lo reparte y lo abre. No es que haya ficción porque el lenguaje esté a distancia de las cosas, sino que la distancia de éstas es el lenguaje, y éste es además la luz y la inaccesibilidad de las cosas, el único simulacro de su presencia. Y todo lenguaje que, en lugar de olvidar esta distancia, se mantiene en ella y la mantiene en sí, todo lenguaje que hable de esta distancia avanzando en ella es un lenguaje de ficción. Es entonces cuando puede atravesar cualquier prosa y cualquier poesía, novela o reflexión, indiferentemente. (Foucault, 1971:23)

Así, Foucault procuraba que una intervención crítica sobre el nouveau roman reverberara hacia el campo teórico, no solo para reconfigurar una imagen de la ficción, sino para conseguir una conceptualización de la distancia como condición constitutiva del vínculo entre el lenguaje y las cosas. Por lo tanto, toda creación discursiva inscribiría la marca de esa distancia en su interior, derribando una reductiva idea de la literatura para expandirse hacia diversas variaciones del pensamiento. Esta indistinción entre palabra literaria y reflexión teórica hacía tangible el rastro de esa distancia aludida, de una inaccesibilidad que Foucault elaboraba como experiencia de la ficción.

Algunos años más tarde, en otra lengua y estribación cultural, el segundo libro de Giorgio Agamben (1995), Estancias: la palabra y el fantasma en la cultura occidental, publicado en 1977, retomaba la genealogía crítica apuntada por los telquelistas para indagar la controvertida yuxtaposición entre poesía y reflexión filosófica. Las consideraciones desarrolladas en el «Prefacio» del 
volumen orientaban algo más que la introducción de un ensayo aislado, y pueden considerase como la instancia preliminar de una sostenida indagación sobre las capacidades del pensamiento y la escritura, luego continuadas en sucesivos textos hasta el presente. ${ }^{2}$ En dicho «Prefacio», Agamben señalaba el final del siglo XVIII y al romanticismo alemán como momento privilegiado en el cual esta discusión habría tomado forma e historicidad para la modernidad occidental. ${ }^{3}$ Su rememoración se alejaba, no obstante, de todo trascendentalismo metafísico para recorrer el espacio ocupado por la crítica en el momento de su irrupción, recuperando para la palabra reflexiva su conexión con lo inasible, cuya figuración es el fantasma.

Desde sus inicios, los trabajos de Agamben no se orientaron hacia la consolidación de un andamiaje positivo para el saber crítico, por el contrario, su investigación constituía el regreso a una instancia en apariencia indiferenciada, cuando la crítica designaba la «indagación sobre los límites de la conciencia, es decir sobre aquello que precisamente no es posible de asentar ni asir» (Agamben, 1995:9). Indagación paradójica, sin dudas, dado que esta dificultosa determinación conspira contra los intentos por restaurar una ilusoria racionalidad del discernimiento, o las potestades de una inteligencia activa distanciada para mejor observación de textos y materiales pasivos. Por lo contrario, la crítica se yergue según Agamben, sobre la paradoja de sus propios límites para luego proyectar esta contradicción como método y exploración sobre la modernidad literaria y la historia del arte. Esta condición paradójica haría de la crítica una práctica que puede reclamar para sí un «carácter creativo» (10), aunque lejos del mero gesto retórico. Para Agamben, la crítica y el arte comparten un horizonte común de creación a través de la radical negatividad que las constituye como «proceso de su irónica autonegación» (10). La reminiscencia al romanticismo de Jena, luego a los textos de Benjamin, permiten despejar cualquier proximidad con una tradición que ubicaría a la crítica al interior de un pensamiento de la trascendencia, como es el caso de las críticas kantianas, según la explícita taxonomía elaborada por Agamben en "La inmanencia absoluta» (2009). Resulta evidente, entonces, la postulación de un campo inmanente en el cual la crítica se encarama sobre la escotadura entre la poesía y la filosofía para reivindicar la potencia creativa (poiética) del pensamiento. De ahí que la crítica se involucre menos con las capacidades del discernimiento y el juicio que con las posibilidades para apuntar al centro vacío de un saber, cuya negatividad revela el funcionamiento (y la vigencia) de una paradoja; escribía en Estancias...

La objeción de Hegel al «señor Friedrich von Schlegel», a Solger, a Novalis y a los otros teóricos de la ironía, según la cual éstos se habrían quedado en la «infinita negatividad absoluta» y habrían acabado por hacer del menos artístico «el verdadero principio del arte», despachando «lo inexpresado por la cosa mejor», deja escapar lo esencial, o sea que la negatividad de la ironía no es la provisional de la dialéctica, que la varita mágica de la Aufhebung está ya siempre en el acto de transformar en algo positivo, sino una negatividad absoluta y sin rescate, la cual sin embargo no renuncia por ello al conocimiento. (Agamben, 1995:10-11)

Al retomar esta discusión el italiano colocaba como nudo del pensamiento crítico la historicidad de una división en el origen de la cultura occidental entre poesía y filosofía, entre palabra lógica-racional y palabra inspirada-estática. Frente a esta cesura, Agamben advertía, «Lo que de este modo queda suprimido es que toda auténtica intención poética se vuelve hacia el conocimiento, así como todo verdadero filosofar está siempre vuelto hacia la alegría» (1995:12). 
Esa territorialidad difusa en la que ambas palabras se confunden es, de hecho, una crisis de la distancia «el momento en que la escisión alcanza su punto extremo» (13). Muy lejos de la pretensión científica que considera la necesidad de una distancia relativa entre el objeto y el sujeto de conocimiento, lejos también de la tradición dominante del logos, para Agamben la crítica efectúa un verdadero programa de investigación en el que pensamiento y poesía se abisman para componer una «ciencia sin objeto» (11), una palabra irónica, fantasmática, contradictoria, fraguada con el signo de la negatividad.

En el centro de este cisma aparentemente irreconciliable se ubicaría, entonces, la crítica; intersección entre la palabra del saber y la palabra del placer que hace visible un enlace nunca completamente realizado. La elaboración agambeniana postulaba una territorialidad utópica para emplazar este encuentro, situando a la crítica en su convergencia irrealizable, aunque infinitamente próxima en «el goce de lo que no puede ser poseído y la posesión de lo que no puede gozarse. (...) Lo que está recluido en la "estancia" de la crítica es nada, pero esta nada custodia la inapropiabilidad como su bien más precioso» (1995:13). Así, la imagen conceptual de la stanza tomada de la tradición trovadoresca actuaba como significativa alusión a una palabra-pensamiento que se vuelve hacia una espacialidad acotada y, sin embargo, capaz de velar por un objeto deseado. En este punto, la escritura de Agamben adquiere el tenor de una verdadera epistemología crítica de las humanidades. Al enfocar la yuxtaposición entre objeto de estudio y sujeto del conocimiento, problema constitutivo de una ciencia sin objeto en la cual se enfoca el análisis a la propia racionalidad y su estructura subjetiva, la exploración crítica se revela como algo más que una simple paradoja: «tal vez la tarea más seria que en nuestro tiempo queda confiada al pensamiento» (11). Agamben señalaba la radical contradicción de la distancia en la práctica crítica para demostrarla, ante todo, como examen sobre las condiciones del pensamiento y la creación conceptual. Así, los itinerarios de la crítica adoptaran la fisonomía de una búsqueda que, sin embargo, no se sintetiza en la consecución de resultados cuantitativos, materialmente tangibles, rudimentariamente fijados en el archivo, sino como cartografía de un espacio inasequible: «Como toda autentica quetê, la quetê de la crítica no consiste en reencontrar su propio objeto, sino en asegurarse de las condiciones de su inaccesibilidad» (11).

A partir del ensayo agambeniano el problema de la distancia se revoca o, al menos, ya no se plantea en una filosofía de la trascendencia y su organización sobre las capacidades del intelecto, los sujetos del saber y los objetos pacientes desmenuzados ante la mirada del cientista social. Sin llegar nunca a una autentica confusión, la exploración crítica en el campo inmanente esbozada por Agamben parte de un saber que es, ante todo, veladura de lo inaccesible, nunca instancia de rigor y ascetismo metodológico. El problema de la distancia «entre palabra poética y palabra pensante» (1995:11) crea las posibilidades para un pensamiento que rebasa sus cristalizaciones y antagonismos, propiciando la expansión del campo inmanente. La exhortación agambeniana rememoraba las condiciones históricas de este corte para leer su inscripción en el fondo de la cultura. A partir de este momento, su propuesta presenta una teoría del fantasma que habita al interior de la epistemología occidental, un pensamiento alzado contra la disciplinada separación entre el «polo estático-inspirado» y el «polo racional-consciente» (12), y la crítica como un contrasaber que hace tangible su radical negatividad. Estas son las condiciones para un pensamiento que se desborda como metáfora en la figuración de una «topología de lo irreal» (15). Más allá de la evidente reminiscencia psicoanalítica, la construcción conceptual agambeniana 
regresa al «topos», ya presente en Aristóteles, para calibrar la complejidad de un espacio sin dudas fantasmático. Este fenómeno de naturaleza espacial, de posicionamiento, permite observar a la crítica como «exploración topológica (...) constantemente orientada a la luz de la utopía» (15) que sin dejar de leer su aspiración oximorónica realiza una «indagación en el vacío» (15). Para Agamben, la crítica sostiene, entonces, una forma de cercanía "con la irrealidad y con lo inapropiable» (15), cuya finalidad utópica será «apropiarse de la realidad y de lo positivo» (15), en una zona de proximidad entre el pensamiento y la palabra poética.

Esta reflexión toma partido en una genealogía de la escritura, la crítica y la negatividad, al punto de reclamar, con el tono de la urgencia, la necesidad del reencuentro de «la unidad de la propia palabra despedazada» (Agamben, 1995:13). Al hacer composible la coexistencia entre la palabra poética y la palabra filosófica, Agamben encontraba, tal como los telquelistas, la potencia de una escritura que reúne ambas valencias, la poiética y la reflexiva, admitiendo sus mutuas reverberaciones. Sus sucesivos trabajos corroboran la continuidad de este linaje de pensamiento inmanente que, atentando contra la escisión originaria, encuentra formas e instancias históricas en que esa distancia fue desestabiliza, desplazada, para finalmente incorporarse como negatividad irreductible.

\section{Ensayo crítico y negatividad en la Argentina contemporánea (breves aproximaciones)}

Resulta innegable advertir cierta estabilización institucional en las estrategias del arte moderno y sus derivas teóricas en el presente. Esta doxa, en ocasiones refugiada en un formalismo anquilosado o un sociologismo mecanicista, actúa simplificando las aristas más incómodas de un pensamiento que, en sus momentos más vitales, fue el espacio para la experimentación estética y la creación conceptual. Sin embargo, el pensamiento de la crítica persiste, y continúa asediando (tal vez burlando) la tajante división entre las formas literarias y la racionalidad que disecciona sus componentes. Esta tensión puede encontrarse en algunos discursos sostenidos en la escena cultural argentina, y permite observar la actualización de una escritura que, ante todo, se presenta como interrogación sobre sus capacidades críticas, situándose por fuera de parámetros esperables, tanto académicos como políticos.

Uno de estos casos se encuentra en los trabajos de Alberto Giordano y sus indagaciones en torno al ensayo, ya sea al enfocar sus modulaciones argentinas o en diálogo con sus célebres cultores europeos (Barthes, Blanchot y Adorno, entre otros). Esta persistencia puede objetivarse al trazar el arco que une sus libros Razones de la crítica (1999), Modos del ensayo. De Borges a Piglia (2005) y El pensamiento de la crítica (2015b). En ese recorrido uno de los textos privilegiados es el «Prólogo» a El discurso sobre el ensayo en la cultura argentina desde los 80 (2015a), en el que numerosos ensayistas se arrojan a la empresa de considerar las derivaciones de esta forma. Más allá de las particularidades de cada una de las intervenciones, el texto de Giordano que abre el volumen actúa como vindicación de una práctica de escritura en la que se reedita (y actualiza) las condiciones de un saber paradójico:

El auténtico pensamiento crítico no propone culturas alternativas, trabaja en los intersticios que abre la emergencia de lo imprevisto para descomponer los fundamentos de la cultura que lo hizo posible y lo limita. El auténtico pensamiento crítico acoge y encausa las potencias de lo incalculable en la dirección 
suplementaria de una repetición creativa (...) El desafío ético del pensamiento crítico es cuidar de lo impensable aunque violente o suspenda el curso de la razón especulativa. (2015a:7-8)

La apuesta constituye una reflexión sobre las condiciones de posibilidad de un saber que se distancia de la cultura afirmativa y el sentido común para dar lugar a una suspensión creativa, en cuyo espacio se aloja y practica la escritura-pensante. Según el itinerario señalado para la cultura argentina es a partir de la década de 1980, momento crispado de desplazamientos en el pensamiento teórico y en la vida política, cuando podría advertirse la legitimación de un «vínculo reproductivo entre investigación y escritura» (Giordano, 2015a:10), su correlato hacia la «clausura académica» (10), y una consecuente «voluntad de homogeneización» (10). El texto de Giordano sugiere que, como efecto colateral de la estabilización institucional luego de la recuperación democrática, el saber y sus formas tienden hacia su cristalización; contra ella el discurso del ensayo compone una fuga polémica frente a la sociabilidad del consenso y la domesticación del pensamiento. En ese contexto, el ensayismo diseña una forma, pero también un modo de procesar las condiciones del saber, una retórica discursiva de "profesores universitarios» (10) que «manifiestan su deseo, íntimo y político (...) de arriesgarse a no encontrar algo inmediatamente valioso para la comunidad de los especialistas con tal de potenciar los propios intereses y las propias facultades, sometiéndolos a la prueba de lo incierto» (10). De modo que la política sutilmente resistente del ensayo crítico recrea la espacialidad de un pensamiento (de una teoría) en estado de perpetua de incertidumbre, sostenido en el gesto y en el acto de la escritura.

Ese «acto de pensar por escrito» (Giordano, 2015a:27) conlleva un cúmulo de tensiones que se sustraen a la certeza de una metodología implacable. Por el contrario, la afirmación de lo «paradójico», lo «fútil», el recurso a la digresión y la demora son algunos de los recursos que el ensayo interpone a «la lógica deductiva» (27) con el objetivo, en absoluto modesto, de denunciar «el conocimiento sistemático» (27). El elogio adorniano que Giordano realiza a esta discursividad informe debe comprenderse como marca identitaria y genealógica; así, las políticas de su escritura emplazan una posibilidad disidente frente a las trivialidades de la vida académica, imaginando un modo díscolo de habitar el claustro, de rodear el orden disciplinar desbaratando las facetas de un pensamiento sólidamente edificado. En su lugar, Giordano insiste en encontrar estribaciones vernáculas de una escritura que ha sido elaborada en la «experiencia del saber como errancia y pasión por lo verdadero» (2015a:27).

Esta indagación sobre la potencia de las formas inconclusas e inconformes del saber se despliegan, asimismo, en los textos de Damián Tabarovsky, escritor ubicado lejos del claustro universitario, aunque con incidencia en la escena editorial. Su ensayo «Negatividad: un rodeo», resultado de una intervención pública y compilado en el volumen Estética de la dispersión (2013), ${ }^{5}$ plantea de modo explícito el retorno a este nodo de la teoría crítica como parte de su propia política literaria. Allí, Tabarovsky traza abiertamente las complejidades de su recuperación, aunque insistiendo en una modulación contemporánea para ese espacio de pensamiento y escritura inaugurado hace dos siglos, el cual encuentra formulaciones en los textos benjaminianos, en los trabajos de Adorno y en las recuperaciones realizadas por Agamben.

La negatividad actual se diagramaría, según Tabarovsky, como posición polémica de las artes frente a un mundo social interconectado y mediatizado, enfrentada a un mercado editorial transnacional que replica modelos de concentración y se disemina en diversos artefactos 
estéticos apropiados por la industria cultural-espectacular. En este panorama se reevalúan las posibilidades para los experimentalismos artísticos y sus correlatos políticos, que Tabarovsky lee a través de los filósofos frankfurtianos, ${ }^{6}$ es decir en diálogo con una noción de negatividad esbozada como distancia que, sin embargo, se reajusta para un presente definido por «el triunfo de lo mediático» (2013:37). En la propuesta de Tabarovsky, la escritura literaria diseña una imaginación «instalada en la negatividad» (37), aunque franqueando la solemnidad política de la cultura crítica y las construcciones molares de sentido especialmente aglutinadas en el concepto de «resistencia»:

Resistencia es una categoría desacertada porque remite a la idea de lo inmodificable, lo eterno, igual a sí mismo. La noción de resistencia siempre alude a un juego de acción y reacción, una presión y algo que resiste, y eso que resiste no muta, no cambia: simplemente resiste. Nada más alejado de la literatura, al menos de la que a mí me interesa. Prefiero entonces pensar en términos de negatividad revisando críticamente la propia categoría tal como proviene de Adorno y de Benjamin y, antes, de la vieja tradición romántica para encontrarle una nueva productividad a la negatividad, valga la paradoja (lo propio de la literatura es inventar paradojas allí donde antes no las había). (37-38)

Esta reformulación de la resistencia como búsqueda de una «nueva productividad» en torno a la negatividad plantea en Tabarovsky la vindicación de una «comunidad inoperante» (2004:17), idea desarrollada en su ensayo «El escritor sin público» reunido en Literatura de izquierda, a partir de la cual propone una imagen paradójica de la literatura a contramano de la tradición académica y, especialmente, de las lógicas del mercado. En ella resuenan el topos irreal agambeniano, también las consideraciones sobre la comunidad construidas por Nancy y Blanchot, es decir, el territorio (o stanza) para un pensamiento y una escritura que se sustraen a cualquier estabilización institucional; de modo que, «esta nueva (o no tan nueva) negatividad de la literatura implica», para Tabarovsky, «una defensa activa de lo intelectual como práctica concreta y como estilo de vida» (2013:38). No se detenta, entonces, una trivial posición antiintelectualista, sino una recuperación de los afectos intelectuales para el tiempo presente. En este contexto, la negatividad implica una vivencia de lo contemporáneo al modo agambeniano, es decir situándolo como experiencia del anacronismo en la que se yuxtaponen vida, pensamiento y escritura más allá de todo valor mercantilizado. Así, la política literaria de Tabarovsky desafía la contradictoria «dispersión concentrada» (2013:38) de una cultura mediática y tecnificada como intento por comprender el lugar de lo literario en el presente. Su conclusión resulta decisiva: «la literatura se encuentra sola, librada a su suerte» (39). Por esto, el retorno a la negatividad y la revisión de sus conexiones con la noción de resistencia pueda ser el síntoma de una fragmentación de la cultura letrada durante las primeras décadas de un siglo que parece dejar atrás los privilegios de su centralidad, su antigua funcionalidad como rasgo de distinción social, para reubicarse como espacio de experimentación e interrogación. La pregunta, incómoda, sería: ¿qué lugar ocupa la literatura en una sociedad que, junto a Reinaldo Laddaga (2006), es posible nombrar como posdisciplinaria? Tabarovsky parece responder a esa interrogación: la literatura se encuentra en la intemperie, en el espacio de una comunidad irreal, fantasmática, inoperante.

En este contexto, las reflexiones de Laddaga en torno a una nueva cultura de las artes señalan el desplazamiento de la crítica como parte de un movimiento general que hacia el final siglo XX 
modifica los modos de lectura y participación en el mundo común. Parte de este desplazamiento reconfigura la soledad del acto artístico y la contemplación de la obra de arte, entendidos por el canon crítico como «la puesta a distancia de un fragmento de materia o de lenguaje» (2006:31). El trabajo intelectual entendido como un «distanciarse» de los objetos y las experiencias para explicar sus condiciones de posibilidad constituye para Laddaga «la forma kantiana de la crítica (...) común en la cultura de la modernidad» (148). En su lugar, una de las posibilidades para el ensayismo novosecular se encuentra, tal como lo demuestra su trabajo, en la observación de instancias comunitarias de producción estética en un régimen ampliado, inespecífico o posautónomo para la cultura de las artes, investigación que puede corroborase en los últimos ensayos de Josefina Ludmer (2010), Néstor García Canclini (2010) y Florencia Garramuño (2015), entre otros.

Ahora bien, las intervenciones de Tabarovsky ofrecen una flexión particular sobre estos problemas, que bien pueden considerarse como pervivencia genealógica de la modernidad en el presente literario, en tanto se admita la condición de un reajuste sobre el propio cuerpo de la teoría crítica. De ahí la necesidad de especificar los vínculos entre la vida y las prácticas intelectuales, del mismo modo que se reinterpreta el concepto de resistencia para conseguir una aproximación que no redunde en posicionamientos definidos desde una elocuencia dogmatizante. Los ensayos y ficciones del escritor ponen a prueba la creación de un espacio de escritura crítica y experimental en el presente; por ello, su propuesta de un regreso a la negatividad en la forma del rodeo, de un retorno desviado a toda certeza sobre las resistencias del arte, se impone como detenimiento explícito: allí donde se instala una molaridad inmutable, provocar su incertidumbre.

En un sentido coincidente, García Canclini (2009) ha realizado una revisión sobre este problema en su ensayo «¿De qué hablamos cuando hablamos de resistencia?», texto que advierte sobre la ausencia de una positividad del concepto al interior de la teoría crítica. En su cartografía, advierte que los disensos de las artes en el contexto general de una sociedad asimétricamente globalizada y tecnificada, cuya dominante cultural es la espectacularización, sin embargo, no aíslan la pregunta por sus capacidades críticas, en tanto produzcan un cambio de escala en el ejercicio del poder. «El arte no nos vuelve rebeldes por arrojarnos a la cara lo despreciable», sostiene García Canclini, «Quizá pueda contagiarnos su crítica, no sólo su indignación, si él mismo se desprende de los lenguajes cómplices del orden social» (2009:29). Esta indagación en torno a las resistencias del acto de creación frente a los dispositivos que administran la vida reconduce hacia las potencias inmanentes de un lenguaje desmarcado tanto de la imposición mercantil como de la voluntad de dominio. Esa misma flexión se encuentra en recientes textos de Agamben, quien ha señalado la condición paradójica del acto creativo en un presente transido por dispositivos biopolíticos e informacionales. Al configurar la potencia política de las artes en una "poética de la inoperosidad» (2016:49), esto es, una suspensión de la acción, Agamben reafirma una capacidad del lenguaje, el color o el sonido para pensarse a sí mismos resistiendo su clausura en un trivial circuito de comunicación. En su lugar, la poética de la inoperosidad provee una imagen del lenguaje en términos spinozianos, «el punto en que la lengua, que ha desactivado sus funciones utilitarias, descansa en sí misma, contempla su potencia de decir» (49).

Estas consideraciones sobre la resistencia y la potencia de la palabra literaria pueden conectarse con las reflexiones de Tabarovsky, ya sea esbozadas en Literatura de izquierda, o desplegadas como relectura sobre el concepto de negatividad. Las elecciones políticas del escritor insisten en postular una «comunidad inoperante» que contiene la capacidad inmanente para «pensar desde 
la literatura, es decir: no clausurar el derecho de la literatura a pensar y a pensarse a sí misma» (2013:38). Entonces, a sus ensayos críticos se une la escritura de una ficción experimental que jaquea los principios y consensos literarios sobre el argumento, la anécdota, el personaje $o$ cualquier dogma narratológico, para desplegar una escritura trabajada como exasperación de velocidades, cartografía de territorios y conjetura sobre las intensidades y afectos del lenguaje, derribando cualquier certeza sobre el fervor del tema y su adecuación mimética. Una belleza vulgar (2011) se compone como apuesta novelística en el horizonte de esa nueva negatividad, al instalar paradojas y digresiones en el mismo acto de la narración.

Ahora bien, en el final de este itinerario no es casual que, junto a las derivas narrativas y conceptuales en torno a la negatividad, el último ensayo publicado por Tabarovsky proponga una restauración fantasmática del momento histórico en el cual «el arte se instaló en un frente de diálogo que alcanzaba la política, la cultura, la sexualidad y la propia economía. Se instaló en el horizonte de lo nuevo que todo lo renueva» (2018:10). «Fantasma de la vanguardia» (2018), compilado en el volumen homónimo, reclama una lectura del presente literario a partir de un programa ya extinto, actúa como rememoración sobre un espectro que, en ocasiones, continúa su recorrido en la escena de la escritura contemporánea. En un presente posvanguardista y posutópico, a un siglo de distancia de esas experiencias históricas, Tabarovsky hace del ensayo y de la novela artefactos de pensamiento en los cuales el lenguaje se abisma, la sintaxis se hiende y la ficción se expande fuera de toda regulación, ya sea disciplinar, académica o de mercado. Su postulación de una lengua literaria enrarecida, habitada por el fantasma del experimentalismo vanguardista, reactualizando sus capacidades para conmocionar y estremecer la institucionalidad del arte, ejecuta un deliberado contragolpe a «los discursos hegemónicos, inclusos de la propia narrativa» (29). Por esto, Tabarovsky recurre al cuerpo muerto de la teoría crítica para reinstalar en la actualidad los espectros del arte experimental y la negatividad, marcas de una identidad e insignias de su política literaria. Al evocar el «fantasma de la vanguardia» su ensayo renueva la fuerte postulación de una comunidad definida como defección a las concesiones banales, comunicativas y mercantiles del lenguaje, dado que, según escribe Tabarovsky «la propia literatura, cuando se vuelve radical, cuando sospecha de ella misma, es una apelación al fantasma» (19).

$\mathrm{Al}$ insistir en ese pasado, en esa genealogía centenaria, Tabarovsky configura algo más que un mero elogio del anacronismo, da lugar a un lenguaje abierto al experimentalismo, construido en el «malentendido» y la «paradoja» (2018:29), habitado por «los restos» (29) de una memoria que oficia como sedimento para las posibilidades de la crítica y sus mestizajes literarios. «Fuera de lugar», «exceso», «sobrecarga» (31), en sus definiciones resuena una experiencia trabajada en la escritura, aunque expandida como forma de vida; de hecho, vale recordar, la vanguardia fue una programática negación de la tajante división entre el arte y el mundo común, un intento por reconducir la experiencia artística hacia la "praxis cotidiana» (Bürger, 2010:31). Entonces, este retorno de la negatividad y la vanguardia en la forma del fantasma y la inoperancia reorganiza las distancias de la teoría (y de la crítica) en un campo de cercanías, para componer un campo inmanente, una comunidad, en la cual coexisten vida y práctica literaria.

En el cruce de estas experiencias, en la memoria de estas escenas, en la modulación persistente de las figuras de la distancia, quizás han podido señalarse algunos detenimientos significativos para la elaboración de una teoría de las artes verbales. Allí, el ensayo crítico se compone como 
acto de creación, como distanciamiento contra la banalidad del automatismo, como espacio de pensamiento que indaga sus propios límites junto a sus posibilidades de expansión, sus zonas limítrofes y mestizajes con otras formas de la palabra, en especial en su potencia poética, es decir, creativa. Sin embargo, al visualizar estas figuraciones de la distancia entre el mundo y los lenguajes que lo componen, la crítica rodea el centro vacío de una incógnita que, sin embargo, se resiste a resolver. La crítica, en la forma del ensayo o la especulación ficcional, crea una distancia irreductible entre el saber hecho acto de escritura y los objetos de su investigación; por eso, se alza contra la voluntad de dominio o la captura definitiva de lo real, y en su lugar solo ofrece la incertidumbre de una escritura fraguada en la precariedad, enfrentada a los fantasmas de su genealogía. Si la crítica aún posee alguna capacidad de resistencia negativa y distanciada, una potencia, quizás se deba a una obstinada comunidad que, escéptica, descree de la progresión de las prácticas trascendentes, de la asepsia cientificista y sus dispositivos, y elige en su lugar la alegría de un saber irónico en continuo recomenzar.

\section{Notas}

1 Según advierte Manuel Asensi Pérez hacia 1963 «la “revista” Tel Quel da paso al "espacio" Tel Quel» dado que «bajo la dirección de Sollers, Seuil acepta abrir una colección de libros (narrativa, poesía, teoría en general) como una extensión de la revista. Esta maniobra editorial iba a resultar fundamental para el devenir de la teoría literaria del siglo XX porque en esa colección se iban a dar la mano los inicios de dicha teoría con su transformación post-estructural, verían la luz tanto los textos de los formalistas rusos como algunas de las obras fundamentales de Barthes, Genette, Sollers, Kristeva, Pleynet o Derrida» (2006:67).

2 De hecho, este recorrido puede considerarse a partir del arco que une sus primeros libros, entre ellos El lenguaje y la muerte. Un seminario sobre la negatividad, en el cual se reúnen las ideas expuestas en los seminarios dictados por Agamben entre 1979 y 1980, y su reciente trabajo titulado El fuego y el relato (2016).

$3 \mathrm{El}$ regreso al momento romántico, por supuesto, no es exclusivo de la lectura de Agamben. De hecho, tal como han señalado Philippe Lacoue-Labarthe y Jean-Luc Nancy en El absoluto literario, cuya primera publicación de 1978 es contemporánea a Estancias, el pensamiento romántico se elaboró como especulación «filosófica del arte y de la poesía» (2012:463), y en un sentido más específico, «se produjo por el encuentro, ante todo, de la filosofía y de la crítica literaria» (463). El perfil filológico y teórico de los hermanos Schlegel, que tanto Lacoue-Labarthe y Nancy como Agamben señalan en el punto originario de la crítica romántica, fue sistematizado en la tesis de Walter Benjamin para la Universidad de Berna. En ese temprano texto de Benjamin la crítica de arte era juzgada «impensable sin unos supuestos gnoseológicos como también sin unos supuestos estéticos» (2000:29), en tanto «la crítica contiene un momento cognoscitivo» (29). Esa condición se fundamenta en el vínculo que la crítica establece con sus objetos, de ahí que la práctica reflexiva conduzca necesariamente a una autobservación del pensamiento que no puede confundirse con un trivial juicio de valor; $y$, de hecho, tal como apuntó la tesis de Benjamin, «Sólo con los románticos se afirmó definitivamente la expresión crítico de arte [Kunstkritiker] frente a las más antigua de juez de arte [Kunstrichter]» (83). Siguiendo el legado benjaminiano, la crítica se sitúa por fuera del juicio de autoridad, acentuando el complemento imaginativo en el cual la tarea filosófica y las prácticas estéticas de confunden.

4 Los ensayistas que conforman el volumen son Raúl Beceyro, Beatriz Sarlo, Eduardo Grüner, Nicolás Casullo, Cristian Ferrer, Horacio González, Américo Cristófalo, Gregorio Kaminsky, Silvio Mattoni, Carlos Kuri y Juan B. Ritvo.

5 En el volumen, compilado por Franco Ingrassia, se reúnen textos de Sergio Raimondi, Ana Longoni, Daniel Melero, Pablo Schanton, Rafael Cippolini, Lucrecia Martel Reinaldo Laddaga, Pablo Hupert y Damián Tabarovksy.

$6 \mathrm{Al}$ respecto, la posición de Adorno resultaba taxativa: «Ni la teoría ni el arte mismo pueden hacer concreta la utopía; ni siquiera en forma negativa. Lo nuevo nos ofrece una 
enigmática imagen del hundimiento absoluto y solo por medio de su absoluta negatividad puede el arte expresar lo inexpresable, la utopía» (1983:51). Así quedaba inscripta en su Teoría estética (1983) una conceptualización de la negatividad y, por lo tanto, una forma de comprender las relaciones entre las artes y sus capacidades para afectar la vida común. De acuerdo a la delimitación descripta por Adorno «la fuerza del distanciamiento» (234), esgrimido como distancia contra «la miseria y la falsedad» (234) realiza su potencia crítica en «la forma de la negación concreta» (234).

\section{Referencias}

Adorno, T. (1983). Teoría estética. Madrid: Hyspamerica.

Agamben, G. (1995). Estancias: la palabra y el fantasma en la cultura occidental. Valencia: Pre-textos.

Agamben, G. (2008). El lenguaje y la muerte. Un seminario sobre el lugar de la negatividad. Valencia: Pre-textos.

Agamben, G. (2009). La inmanencia absoluta. En Giorgi, G. y Rodríguez, F. (eds.). Ensayos sobre biopolítica. Excesos de vida (pp. 59-92). Buenos Aires: Paidós.

Agamben, G. (2016). El fuego y el relato. Madrid: Sexto piso.

Amícola, J. (1997). De la forma a la información. Rosario: Beatriz Viterbo.

Arro, E. (2008). Una polémica en torno al lenguaje de la crítica literaria. Anclajes, XI-XII, 9-20.

Asensi Pérez, M. (2006). Los años salvajes de la teoría. Valencia: Tirant lo Blanch.

Barthes, R. (1994). El susurro del lenguaje. Más allá de la palabra y de la escritura. Barcelona: Paidós.

Barthes, R. (2000). Crítica y verdad. México D.F.: Siglo XXI.

Benjamin, W.(1998). Tentativas sobre Brecht. Iluminaciones III. Madrid: Taurus.

Benjamin, W. (2000). El concepto de crítica de arte en el romanticismo alemán. Barcelona: Península.

Bertón, S. (2013). El «espacio Tel Quel» y la configuración de una discursividad vacilante. Revista Pilquen, 16, 1-10.

Bürger, P. (2010). Teoría de la vanguardia. Buenos Aires: Las Cuarenta.

Eichenbaum, B. (1978). El método formal. En Todorov, T. (ed.). Teoría de la literatura de los formalistas rusos (pp. 21-54). México D.F.: Siglo XXI.

Foucault, M. (1971). Distancia, aspecto, origen. En Redacción Tel Quel (ed.), Teoría de conjunto (pp. 12-28). Barcelona: Seix Barral.

Foster, H. (2001). El retorno de lo real: la vanguardia a finales de siglo. Madrid: Akal.

García Canclini, N. (2009). ¿De qué hablamos cuando hablamos de resistencia? Estudios visuales, (7), 16-37.

García Canclini, N. (2010). La sociedad sin relato. Antropología y estética de la inminencia. Buenos Aires: Katz.

Garramuño, F. (2015). Mundos en común: ensayos sobre la inespecificidad del arte. Buenos Aires: Fondo de Cultura Económica.

Giordano, A. (1999). Razones de la crítica. Sobre literatura, ética y política. Buenos Aires: Colihue.

Giordano, A. (2005). Modos del ensayo: de Borges a Piglia. Rosario: Beatriz Viterbo.

Giordano, A. (2015a). Prólogo. El discurso sobre el ensayo. En Giordano, A. (ed.). El discurso sobre el ensayo en la cultura argentina desde los 80. Buenos Aires: Santiago Arcos.

Giordano, A. (2015b). El pensamiento de la crítica. Rosario: Beatriz Viterbo.

Hellín Nistal, L. (2016). Una travesía política: el extrañamiento de Brecht como propuesta transformadora de la desautomatización del formalismo ruso. Castilla. Estudios de Literatura, 7, 461-491.

Jakobson, R. (1978). Hacia una ciencia del arte poético. En Todorov, T. (ed.). Teoría de la literatura de los formalistas rusos (pp. 7-10). México D.F.: Siglo XXI.

Lacoue-Labarthe, P.; Nancy, J.L. (2012). El absoluto literario: teoría de la literatura del romanticismo alemán. Buenos Aires: Eterna Cadencia.

Laddaga, R. (2006). Estética de la emergencia. Buenos Aires, Argentina: Adriana Hidalgo. 
Ludmer, J. (2010). Aquí América Latina. Una especulación. Buenos Aires: Eterna Cadencia.

Norris, C. (2002). Extrañamiento. En Payne, M. (ed.) Diccionario de teoría crítica y estudios culturales (pp. 281-282). Buenos Aires: Paidós.

Redacción de Tel Quel (1971). División del conjunto. En Redacción de Tel Quel. Teoría de conjunto (pp. 7-11). Barcelona: Seix Barral.

Shklovski, V. (1978). El arte como artificio. En Todorov, T. (ed.). Teoría de la literatura de los formalistas rusos (pp. 55-70). México D.F.: Siglo XXI.

Saussure, F. (1945). Curso de lingüística general. Buenos Aires: Losada.

Tabarovsky, D. (2004). Fantasma de la vanguardia. Rosario: Beatriz Viterbo.

Tabarovsky, D. (2011). Una belleza vulgar. Buenos Aires: Mardulce.

Tabarovsky, D. (2013). Negatividad: un rodeo. En Ingrassia, F. Estética de la dispersión (pp. 33-40). Rosario: Beatriz Viterbo.

Tabarovsky, D. (2018). Fantasma de la vanguardia. Buenos Aires: Mardulce. 